\title{
EXPERIÊNCIAS DE ENSINO DE HISTÓRIA DA AMÉRICA E HISTÓRIA INDÍGENA NA AMAZÔNIA ORIENTAL: ENTRE DEMANDAS ACADÊMICAS E FORMAÇÃO DOCENTE
}

\author{
RESEARCH AND TEACHING EXPERIENCES IN THE FIELDS OF HISTORY \\ OF THE AMERICAS AND NATIVE BRAZILIAN HISTORY: CHALLENGES OF \\ TEACHER TRAINING IN THE EASTERN AMAZON REGION
}

\author{
Maria Clara Sales Carneiro Sampaio ${ }^{1}$ \\ Valéria Moreira Coelho de Melo ${ }^{2}$ \\ Erinaldo Cavalcanti ${ }^{3}$
}

\begin{abstract}
RESUMO: O presente artigo tem como objetivo contribuir para a reflexão acerca da formação docente no que tange aos conteúdos de ensino de História das Américas e História Indígena, estabelecendo um diálogo com a Lei $\mathrm{n}^{0} 11.645$, de 10 de março de 2008. Partir-se-á das experiências desenvolvidas na Faculdade de História (FAHIST) da Universidade Federal do Sul e Sudeste do Pará (Unifesspa), na cidade de Marabá, na Amazônia Oriental.
\end{abstract}

PALAVRAS-CHAVE: Ensino de História. História da América. História Indígena. Relações Étnico-raciais.

ABSTRACT: This following article has as a main objective to contribute and to reflect about teacher's training concerning to the contents of History of the Americas and Native-Brazilian History teaching through a dialogue with the Brazilian Law 11.645/08. It begins with the experiences lived at the Faculdade de Historia (FAHIST) of Universidade Federal do Sul e Sudeste do Pará (UNIFESSPA), located at the Marabá city, in the Eastern Amazon Region.

KEY-WORDS: History Teaching; History of the Americas; Indigenous History; Ethnic-Racial Relationships.

\footnotetext{
${ }^{1}$ Doutora em História Social pela Universidade de São Paulo. Professora Adjunta e Coordenadora da Pós-Graduação Lato Sensu da FAHIST/Unifesspa, é especialista em História Social e da Escravidão Atlântica.

${ }^{2}$ Doutora em Antropologia pela Universidade Federal do Amazonas. Professora Adjunta da Unifesspa. Desenvolve pesquisas na área de etnologia indígena.

3 Doutor em História pela Universidade Federal de Pernambuco. Professor Adjunto e Diretor da Faculdade de História (FAHIST) da Unifesspa. Atua nas áreas de Teoria, Ditadura Militar, Ensino de História e Formação Docente.
} 
Entre a aprovação da Lei $\mathrm{n}^{\mathrm{o}} 10.639$, de 9 de janeiro de 2003 - que tornou obrigatório o ensino de história e cultura afro-brasileira e africana para o ensino básico - e a aprovação da Lei $n^{\circ} 11.645 / 2008$ (que incluiu também a questão indígena), passaram-se cinco anos. São muitas - e provenientes de disputas políticas plurais - as especificidades das razões políticas que acarretaram na demora para a inclusão da história dos muitos povos indígenas brasileiros na educação para as relações étnicoraciais. Contudo, pode-se pensar que a demora, por si só, é emblemática no que tange à forma como as contribuições histórico-sociais indígenas para formação da sociedade brasileira ainda são vistas como marginais, ou de menor importância.

Às vésperas de completar sua primeira década de vigência, a Lei $n^{\circ} 11.645 / 2008$ ainda enfrenta muitos desafios em sua aplicabilidade, que abarca a obrigatoriedade do estudo de história e cultura indígena “[...] nos estabelecimentos de ensino fundamental e de ensino médio, públicos e privados [...]" (BRASIL, Lei 11.645, 2008, artigo 26-A), situação também presente nos estabelecimentos de ensino superior.

A partir das experiências de ensino de história das Américas e história indígena, vivenciadas no curso de licenciatura em história da Unifesspa, o objetivo do presente artigo é oferecer contribuições acerca do papel das instituições de ensino superior na formação de professores e professoras para atuação no ensino básico. Para tanto, partiremos das experiências recentes desenvolvidas na FAHIST/Unifesspa, na cidade de Marabá, na Amazônia Oriental.

A criação do curso de História, em 2014, respeitou a perspectiva de ampliação da formação de professores e professoras para a atuação na educação básica no “[...] contexto sócio histórico da Amazônia Oriental brasileira e, particularmente, da mesorregião sudeste do Pará [...]" (SILVA, 2013, p. 4). Nesse sentido, faz-se necessário ressaltar que a criação da Unifesspa se deu em uma lógica de ampliação da universidade pública para o interior da Amazônia, processo análogo ao da fundação da Universidade Federal do Oeste do Pará (UFOPA). Unifesspa e UFOPA, assim, fizeram parte de uma política que objetivava a redução de desigualdades regionais pela via da ampliação de investimentos em educação:

A promoção de políticas afirmativas na Unifesspa é resultado da influência das medidas adotadas pela Universidade Federal do Pará (UFPA) para garantir o acesso ao ensino superior de grupos sociais historicamente desfavorecidos, sendo que os primeiros registros de ingresso de indígenas, 
assim como todo o processo de discussão e criação de reserva de vagas para quilombolas, ocorreram quando a Unifesspa não havia sido criada. ${ }^{4}$

A mesorregião Sudeste do Pará é palco de processos sociais muitos específicos. Até meados da década de 1960, a presença indígena nessa região se somava a uma população de diferentes grupos de migrantes. O município de Marabá, por exemplo, foi fundado no final do século XIX às margens do Rio Tocantins, espaço habitado por diferentes povos indígenas. Entre as atividades econômicas da região, estavam o extrativismo de produtos da floresta, bem como a pecuária e a pesca. A exploração e o comércio do látex do caucho e, mais tarde, as atividades com a castanha-do-pará, concorreram para impulsionar o crescimento de uma população não-indígena na paisagem social desta parte do território paraense.

A partir das décadas de 1970 e 1980, se somaram a essa população, já bastante diversa, “[...] os camponeses nordestinos e norte-goianiense, empresários, fazendeiros e comerciantes do Centro-Sul do Brasil [...]" (Idem, p. 10). Conforme demonstra a pesquisa o acirramento dos conflitos sociais, que até hoje se encontram presentes, deuse também a partir da

[...] implantação de infraestrutura rodoviária; a instalação de projetos agropecuários; a propaganda da colonização agrícola; a instalação de canteiros de obras; especialmente a construção da barragem de Tucuruí; a implantação do Projeto Carajás; e a descoberta da mina de ouro de Serra Pelada [...]. (Idem, ibidem).

Essas experiências demonstram a pluralidade de sujeitos e a diversidade do espaço histórico e político no qual se encontram inseridas as atividades de ensino de história das américas e história indígena aqui problematizadas.

Nossa experiência de tempo está, cada vez mais, marcada por uma elevada produção, circulação e disputas de narrativas em redes sociais, cinemas, telenovelas, seriados, literatura entre outras. Nesse cenário polissêmico, pode-se questionar o que ensinar em história para jovens que irão atuar na docência. Que experiências trazem os discentes, vivendo nessa parte da Amazônia, que podem contribuir com as reflexões aqui apontadas? O que ensinar em história das américas e história indígena na Amazônia para os futuros professores? Como ensinar história, respeitando não apenas a

\footnotetext{
4 Trata-se da "Pesquisa Diagnóstico: Programa de Acolhimento Estudantil \& Diversidade Indígenas e quilombolas na Unifesspa - 2016", produzida pela Pró-Reitoria de Extensão e Assuntos Estudantis da Unifesspa. Disponível em:

https://proex.unifesspa.edu.br/images/conteudo/proex/Editais/PESQUISA DIAGNOSTICO Acolhiment o Estudantil e Diversidade 2016.pdf, p. 15, consultada em 09/12/2017, às 21:53.
} 
diferença cultural, mas também as histórias e historicidades diversas que os alunos indígenas trazem para a universidade?

A matriz curricular do curso, ou o chamado Projeto Político Pedagógico, se constitui no primeiro vetor condicionante - mas não necessariamente determinante que direciona certas práticas no que tange à oferta de um conjunto de disciplinas que permite certas abordagens e outras não. As matrizes curriculares são, portanto, projetos fabricados com lentes interpretativas, forjadas nas lutas políticas das experiências temporais. Nesse sentido, não são projetos estáticos. Com ritmos e direções variadas, expressam, revelam e se constituem como uma estratégia política de produzir ciência. Por conseguinte, selecionam, inserem, silenciam, recortam e nomeiam, em diferentes momentos, o que consideram legítimo e indispensável para sua construção.

As matrizes curriculares das licenciaturas em História são, também, projetos políticos por meio dos quais se formam professores, ou seja, são espaços de formação de formadores. Em última instância, é por meio desses documentos produzidos nos departamentos de História que estarão sendo formados os professores e professoras que atuarão no ensino da história em escolas públicas e privadas no ensino fundamental, já que, no ensino médio, o ensino de história foi abolido pela Lei $\mathrm{n}^{\mathrm{o}} 13.415$, de 16 de fevereiro de 2017.

Entre as experiências desenvolvidas, destacam-se os estudos e algumas alterações realizadas pelos professores no Projeto Político Pedagógico do curso de licenciatura em História. Nesse sentido, as reflexões deste artigo também esboçam algumas inquietações a partir do lugar de fala de seus autores. Uma dessas preocupações que são comuns ao corpo docente diz respeito à formação do professor de história que irá atuar, sobretudo, na região amazônica. Ou seja, ensinar história para o público da região amazônica teria alguma especificidade? De maneira ainda mais específica, ensinar história das américas e história indígena para esse público - que também é formado pelas relações que mantêm com as sociedades indígenas presentes na Amazônia Oriental - exigiria alguma singularidade?

Quais as possibilidades de conectar essas complexas questões, articulando-as na construção de uma narrativa crítica na formação docente? Vamos direcionar o ângulo de percepção para a matriz curricular do curso de licenciatura em História da Unifesspa para entender sua configuração no que tange à oferta das disciplinas voltadas para as questões abordadas neste artigo. A matriz curricular encontra-se dividida em dois núcleos: o Núcleo de Formação Docente e o Núcleo de Formação Histórico e 
Historiográfico. Este é formado por quatro áreas, que são: Teoria e Metodologia da História; História Geral; História das Américas e História do Brasil. As áreas, por sua vez, são formadas pelas disciplinas ligadas às respectivas temáticas de cada uma delas. ${ }^{5}$

A Área de História das Américas encontra-se distribuída em quatro componentes curriculares: Sociedades Autóctones das Américas; Conquista e Colonização das Américas; Independências e Formação dos Estados Nacionais nas Américas e Populismo, Revoluções e Regimes Totalitários na América Latina. A área de História da Amazônia, por sua vez, é composta pelas disciplinas: História da Amazônia; História do Sul e Sudeste do Pará; História Social e Econômica da Amazônia; História Indígena e do Indigenismo na Amazônia e Cultura e Natureza na Amazônia. ${ }^{6}$

Entre as mudanças no PPC, ressalta-se a alteração no título da nucleação que passou de "História Americana" para "História das Américas". Essa mudança é consequência de uma necessidade de evidenciar a multiplicidade daquelas sociedades que se desenvolveram nos períodos anteriores ao do estabelecimento de diferentes sistemas coloniais. Ainda que a produção historiográfica recente, bem como os estudos de arqueologia amazônica, compreendam as sociedades ameríndias pela lente do contato entre elas, é inegável que as construções simbólicas dessas inúmeras culturas variem muito, tanto nas vastas extensões do continente como em diferentes momentos históricos. As mudanças realizadas foram fundamentadas na concepção pedagógica, por meio da qual se interpreta os processos históricos do Brasil e da região amazônica, em uma perspectiva de histórias conectadas com outras sociedades americanas.

Os componentes curriculares que tematizam as reflexões aqui abordadas, bem como as experiências de formação e atuação dos docentes que ministram aquelas disciplinas, vão se tornando condição de possibilidades para as atividades de ensino de História das Américas e História Indígena. Durante o período de reformulação da matriz curricular, teve-se a necessidade de estudar algumas leis ligadas à educação, à formação docente do professor de História, entre outras normativas que regulamentam os cursos de licenciatura. De forma específica para os objetivos deste artigo, destaca-se a Lei $\mathrm{n}^{\mathrm{o}}$ 11.645/2008. ${ }^{7}$ Essa lei revogou a Lei $n^{\circ} 10.639 / 2003$. O texto daquele dispositivo é

\footnotetext{
${ }^{5}$ Para outras informações mais detalhadas ver o Projeto Pedagógico do Curso (PPC) de Licenciatura em História disponível no endereço: https://historia-maraba.unifesspa.edu.br/cursol.html

${ }^{6}$ Temos ainda outras disciplinas na "Área de História do Brasil" que se encarregam de tematizar questões ligadas à problemática de análise aqui.

${ }^{7}$ Gostaríamos de expressar que as discussões aqui apresentadas se inserem em um movimento de reflexão amplo que já consta com inúmeras pesquisas e publicações de diversos profissionais que se dedicam ao estudo da referida lei em diferentes perspectivas. Para ampliar do debate ver Bittencourtt $(2005,2012)$,
} 
bastante conciso e sentencia a obrigatoriedade no ensino fundamental e médio na rede pública ou privada, do estudo da história e cultura afro-brasileira e indígena.

\section{Identidade, Políticas Educacionais e História Recente}

Parecem permanecer no senso comum as noções de que a presença de populações indígenas ainda é restrita à região Norte do País e a zonas rurais e/ou de floresta. Dados sobre a presença urbana e sobre os números dessa população, contudo, vêm mudando e desafiando essas visões. Em entrevista para o jornal $O$ Globo, em 2013, a antropóloga Manuela Carneiro da Cunha ponderava que o substancial crescimento da população indígena brasileira - que era cerca de 294 mil pessoas, em 1993, e cerca 817 mil, segundo o Censo do Instituto Brasileiro de Geografia e Estatística (IBGE) de 2010 - era fruto não apenas do crescimento vegetativo, mas de uma questão identitária: “O que realmente mudou é que ser índio deixou de ser uma identidade da qual se tem vergonha. Índios que moram nas cidades, em Manaus, por exemplo, passaram a se declarar como tais $[\ldots] " .8$

A valorização da pertença em relação a uma nova perspectiva do que é ser índio no Brasil tem permeado processos sociais recentes e em muito contribuído para uma lenta transformação na maneira como ainda se vê a cultura e a história indígena como uma história do "outro". Nos discursos do senso comum, esse "outro" ainda parece permanecer distante no espaço, posto que não é incomum que se acredite que as populações indígenas vivem apenas nos espaços de florestas. Esse "outro", indígena, parece permanecer também distante no tempo, uma vez que o índio representado no senso comum ainda é frequentemente associado com imagens coloniais. Essas noções e imagens, conquanto venham se modificando, ainda permanecem homogeneizando sob a categoria de "índio", diferentes grupos étnicos, que têm em comum talvez, apenas as experiências de resistência e dessa identidade que se tornou politicamente operante.

De acordo com senso do IBGE de 2010, a população indígena no Brasil corresponde a aproximadamente $0,44 \%$ da população total do País. Em termos oficiais,

Almeida (2012), Silva (2012) Medeiros (2012) Fernandes (2012), (Russo, 2016), Bergamaschi (2012), Passos (2002), Pereira (2011), Oliveira (2015), Silva (2012).

${ }^{8}$ CUNHA, Manuela Carneiro da. "O Futuro dos índios: entrevista com Manuela Carneiro da Cunha. FREITAS, Guilherme. O Globo, 16/02/2003, Disponível em: http://blogs.oglobo.globo.com/prosa/post/ofuturo-dos-indios-entrevista-com-manuela-carneiro-da-cunha-486492.html, consultado em 07/12/2017, às 17:54) 
as populações indígenas figuram minoria numérica e étnica. A linguagem numérica e oficial, contudo, articula a questão da minoria e o próprio termo "índio", de forma demasiadamente simplificada e desconsiderando a multiplicidade de contextos e a complexidade da questão indígena no Brasil.

Para problematizar a ideia de minoria, podem ser usadas informações acerca de alguns municípios com maioria indígena, como é o caso de Uiramutã, no estado de Roraima, onde $88,14 \%$ da população se autodeclara índio. Outro caso é o do município de Marcação, no estado da Paraíba, onde esse percentual é de 77\%. Essa representação não fica restrita a casos isolados. Grandes cidades como São Paulo ${ }^{9}$ ou pequenos municípios como Ipuaçú, no estado de Santa Catarina, contam com uma população indígena considerável, como mostra a Agência de Notícias do IBGE, em artigo de 18 de abril de 2012:

Segundo o Censo de 1991, em 34,5\% dos municípios brasileiros residia pelo menos um indígena autodeclarado. No Censo de 2000, esse percentual cresceu para $63,5 \%$ e, de acordo com o Censo 2010 , chegou a $80,5 \%$ dos municípios brasileiros. ${ }^{10}$

A inclusão dessa multiplicidade de realidades, nas narrativas sobre as populações indígenas, tem se mostrado uma efetiva ferramenta para a desconstrução das visões comuns sobre a representação de índio restrito apenas à região Norte do País ou apenas à zonas rurais. Outro aspecto que precisa ser melhor pormenorizado e evidenciado é certamente o crescimento da população autodeclarada indígena quando se comparam os dados do IBGE referentes aos censos de 1991, 2000 e 2010, quando o número absoluto dessa população foi de 306.245, 734.131 e 817.963 pessoas, respectivamente. ${ }^{11}$ Os dados apontam, portanto, que apenas entre os anos de $1991 \mathrm{e}$ 2000 teria havido um crescimento de $150 \%$ dessa população. Mais que ao aumento da taxa de fecundidade, esse número nos remete a outros fatores que influenciam

\footnotetext{
${ }^{9}$ Na página oficial da Comissão Pró-Índio de São Paulo, consta o texto sem data "Sim, existem índios em São Paulo" como elucidativo dessa visão relativamente comum de que a presença de populações indígenas é algo relegado ou ao passado colonial ou realidade apenas de outras regiões do Brasil. (Disponível em: http://www.cpisp.org.br/indios/html/apresentacao.aspx, consultado em 08/12/2017 às 18:43).

10 Disponível em: https://agenciadenoticias.ibge.gov.br/agencia-sala-de-imprensa/2013-agencia-denoticias/releases/14204-asi-entre-1991-e-2010-populacao-indigena-se-expandiu-de-345-para-805-dosmunicipios-do-pais.html, consultado em 07/12/2017, às 13:22).

${ }^{11}$ Essas informações sintetizam um conjunto de dados disponíveis no site do IBGE. Elas estão também disponíveis no endereço https://pib.socioambiental.org/pt/c/no-brasil-atual/quantos-sao/o-censo-2010-eos-povos-indigenas < Acesso em $10 \mathrm{de} \mathrm{dez,} \mathrm{2017>}$

É uma citação indireta. O parágrafo sintetiza ideias gerais.
} 
diretamente esses dados. Nos censos do IBGE de 1991 e 2000, a categoria "indígena" aparecia apenas na amostra no tocante aos quesitos de cor ou raça. O censo de 2010 expandiu a investigação sobre a presença indígena com critérios adicionais que incluíam "o pertencimento étnico, a língua falada no domicílio". ${ }^{12}$

Nesse sentido, o trabalho do antropólogo João Pacheco de Oliveira (2016) contribui para a compreensão desse fenômeno. A partir da análise de estimativas oficiais da população indígena, desde o primeiro censo nacional de 1872, Oliveira procurou mostrar como as formas de classificação e, consequentemente, as realidades retratadas pelos censos, são profundamente influenciadas pela ideologia da política indigenista e pelos projetos de governo nos diferentes períodos históricos. Assim, enfatizando a importância do contexto sociopolítico - no qual estão inseridos os grupos étnico-raciais - e a conotação que categorias como, negro, caboclo, índio e pardo assumem em diferentes momentos, o autor retrata os múltiplos fatores que influenciam tanto os critérios de classificação quanto o ato de um indivíduo se declarar parte ou não de uma das categorias classificatórias que figuram nos censos.

Não se pode perder de vista que o termo "índio" foi criado e atribuído por pessoas que não fazem parte do grupo entendido como tal e, por isso, diz respeito, antes de tudo, a uma classificação estrangeira e genérica. As sociedades autóctones das américas, marcadas que são pela diversidade, pelas disputas e pelas histórias particulares, dificilmente poderiam se sentir parte de um mesmo coletivo. O mesmo se pode dizer da imagem que se construiu do que vem a ser índio a partir de estereótipos negativos e da pressuposição do isolamento das formas sociais indígenas no tempo e no espaço. Cientes da distância que havia entre o que a sociedade envolvente entendia como índio e aquilo que pensavam sobre si próprios, não é de se estranhar que muitos indivíduos e comunidades não aceitassem essa designação ao longo do tempo. Não aceitavam porque não se enxergavam nela.

Entretanto, observa-se que essa classificação, por muito tempo usada como sinônimo de barbárie, atraso e primitivismo passa por um processo de ressignificação importante que tem início na década de 1970. No texto "No Brasil todo mundo é índio exceto quem não é” (2005), o antropólogo Eduardo Viveiros de Castro explica que esse processo foi impulsionado pela reação indígena e indigenista ao projeto do governo

12 Disponível em: https://agenciadenoticias.ibge.gov.br/agencia-sala-de-imprensa/2013-agencia-denoticias/releases/14204-asi-entre-1991-e-2010-populacao-indigena-se-expandiu-de-345-para-805-dosmunicipios-do-pais.html, Consultado em: 09/12/2017, às 22:12). 
militar que tinha como objetivo emancipar os índios. Tendo como parâmetro a imagem do índio do início da colonização, alegava-se que, em virtude do contato continuado com a sociedade do entorno, boa parte dos índios não seria mais "índio de verdade". Entretanto, mais do que entender ou estabelecer o que era ou não ser índio, esse projeto tinha como objetivo mais imediato liberar as terras ocupadas por povos indígenas às frentes de expansão que mais uma vez avançavam sobre elas. Esse avanço foi especialmente sentido pelos povos indígenas da Amazônia, em virtude da ênfase no plano de integração geopolítica e econômica dessa região. ${ }^{13}$ Povos com os Parakanã, os Gavião-Akrãtikatêjê e os Aikewara, habitantes da região sul do Pará, têm sua história marcada por deslocamentos compulsórios e pela intrusão de seus territórios pelos impactos de grandes projetos econômicos.

De acordo com o antropólogo Eduardo Viveiros de Castro (2008, p.138), ao “[...] resgatar a questão indígena do folclore de massa a que havia sido reduzida [...]" e despertar os índios para o fato de que "[...] se eles não tomassem cuidado, iam deixar de ser índios mesmo [...]", a tentativa dos militares de "desindianização" surtiu um efeito contrário. Como reação, segundo o autor, desde então observa-se um esforço no sentido de “[...] converter, reverter, perverter ou subverter (como se queira) o dispositivo de sujeição armado desde a Conquista de modo a torná-lo dispositivo de subjetivação; deixar de sofrer a própria indianidade e passar a gozá-la [...]" (2008, p.141). Viveiros de Castro explica, nesse sentido, que a vergonha sistematicamente inculcada por formas múltiplas de violência - e que levou, em alguns casos, indivíduos e coletivos a invisibilizarem sua identidade - cedeu lugar às reivindicações por status diferenciado permanente "dentro da chamada comunhão nacional" (idem, ibidem). Esse processo de mobilização política ganhou corpo por meio do surgimento de muitas associações indígenas e indigenistas que tiveram um papel fundamental em viabilizar mudanças significativas na Constituição de 1988.

Em um esforço de reconhecimento da pluralidade étnica e cultural do País, o texto constitucional marcou uma mudança importante na relação entre o estado e as minorias, que teve como consequência o fortalecimento político da ideia de etnia. Nesse sentido, essa ideia passou a ser mobilizada na luta por direitos, dentre eles o direito à diferença. Esse processo diz respeito, também, ao esforço do movimento indígena em

\footnotetext{
${ }^{13}$ No que diz respeito à questão indígena na Amazônia Oriental no período da ditadura militar, ver Ferraz (1998); Ferraz \& Ladeira (1991). Uma reflexão sobre os conflitos fundiários nessa região, decorrentes das políticas do período em questão, pode ser encontrada em Pereira (2015).
} 
assumir o protagonismo na discussão do que é ser índio no Brasil. Se a multiplicidade de povos, línguas, história de contato não permite que se estabeleça uma fórmula canônica, argumenta-se, hoje, que ser índio não é “[...] uma questão de cocar de pena, urucum e arco e flecha, algo de aparente e evidente, mas sim uma questão de 'estado de espírito'. Um modo de ser e não um modo de aparecer [...]” (Idem, p.136).

No que tange ao direito à diferença, a Convenção 169 da Organização Internacional do Trabalho (OIT), de 1989, prevê que se trata da possibilidade de se estabelecer com a sociedade mais ampla uma relação que não seja pautada no preconceito, o que passa, necessariamente, pela educação. Dentre outras providências, o artigo 31 dessa convenção enfatiza a necessidade de " [...] medidas de caráter educativo em todos os setores da comunidade nacional, e especialmente naqueles que estejam em contato mais direto com os povos indígenas, com o objetivo de eliminar os preconceitos [...]", eventualmente nutridos em relação a eles. Para tanto, o texto legal recomenda que seja assegurado que "[...] livros de História e demais materiais didáticos ofereçam uma descrição equitativa, exata e instrutiva [...]" das sociedades e culturas dos povos indígenas.

$\mathrm{Na}$ esteira dessas inovações legais, tornou-se obrigatório o estudo de história e cultura indígena nas escolas de educação básica e nos currículos de formação docente, por meio da Lei $n^{\circ} 11.645 / 2008$. A instituição dessa lei, de alguma maneira, remete ao reconhecimento da invisibilidade a que, por muito tempo, o ensino de história relegou às populações indígenas e negras. Essa lei serve de base para o desenvolvimento do papel fundamental da disciplina no propósito de tornar possível o estabelecimento de um diálogo étnico-cultural mais respeitoso, embasado no reconhecimento de saberes, histórias, culturas e modos de vida próprios dos povos originários.

Assim, no caso das políticas educacionais, o discurso da pluriculturalidade, observado no texto constitucional, tem como reflexo a ênfase na necessidade de uma “[...] educação para a alteridade [...]” (FLEURI, 2003, p.17), ou seja, uma educação que forme cidadãos sensíveis às diferenças de várias ordens e conscientes da importância da garantia de que essas diferenças não constituam empecilho a igualdade de direitos, de dignidade e de oportunidades. Segundo Reinaldo Matias Fleuri, uma educação pautada na ideia de interculturalidade "[...] pretende contribuir para superar tanto a atitude de medo quanto a de indiferente tolerância ante o 'outro', construindo uma disponibilidade para a leitura positiva da pluralidade social e cultural [...]" (idem, ibdem). 
A despeito desses avanços, a maioria dos brasileiros e brasileiras sabem pouco, ou quase nada, sobre os quase 900 mil índios do último censo. O mesmo pode ser dito sobre as sociedades indígenas presentes em outras partes das américas. Nesse sentido, o desconhecimento ainda é um dos principais empecilhos para que essa educação para alteridade, sobre a qual fala Fleuri, seja possível. Mas por que se sabe tão pouco a respeito dessas populações? Por que nos interessamos tão pouco em saber? De onde brota a indiferença e/ou o preconceito nutrido em relação a elas?

\section{Ensinar e Aprender História Indígena da Amazônia Oriental}

O espaço conferido aos povos indígenas nos currículos de história da educação básica e dos cursos de graduação, bem como a narrativa produzida e veiculada nos livros didáticos, constituem um meio de construir ou desconstruir o interesse por essa temática. Como nos lembra o historiador Eduardo Natalino dos Santos, a escolha ou exclusão de determinados grupos das linhas de pesquisas e dos currículos está fundamentada não apenas em pressupostos teóricos, mas também em escolhas políticas, e afeta, "[...] com maior ou menor intensidade, a visão que nossa sociedade tem dos grupos escolhidos ou relegados pelos historiadores [...]" (SANTOS, 2014, p.18).

O historiador John Monteiro, por sua vez, chama a atenção para o fato de que o crescimento da população indígena - contrariando as projeções de desaparecimento e, sobretudo, a capacidade mobilização política desses em prol da garantia de direitos deixou evidente o quão problemático era o entendimento, por parte da historiografia tradicional, das sociedades indígenas. Essa historiografia, herdeira da classificação das diversas populações indígenas como "povos sem história", por vezes permanece trabalhando com essas sociedades em uma perspectiva de seu congelamento no tempo e no espaço. Na complicada condição atribuída de povos ágrafos, negou-se aos índios brasileiros o lugar de sujeitos históricos por muitos anos. Acabavam por ser, assim, tidos como povos sem passado. Da mesma forma, a partir do pressuposto da incapacidade de esses povos reelaborarem suas diferentes formas de organização sociocultural, diante dos fatos e dos efeitos do contato, esses também eram considerados como povos sem futuro. Entretanto, segundo Monteiro (2001), a partir da década de 1980 observa-se o aumento e uma mudança de perspectiva das pesquisas direcionadas à história indígena no Brasil. Essa mudança se deveu, em muito, às análises mais críticas 
das fontes oficiais, ao reconhecimento da tradição oral como documento, ao diálogo interdisciplinar e à atenção dada ao protagonismo indígena.

Mesmo com os avanços dos últimos anos, a experiência de trabalhar com disciplinas relacionadas à questão indígena em um curso de graduação em História às vezes nos coloca diante de relatos que enfatizam a falta de afinidade com essa temática. Frente aos temas de história antiga, medieval e a história recente, tidos geralmente como mais atraentes, raramente alunos e alunas que frequentam a licenciatura em história da Unifesspa têm demonstrado interesse por qualquer aspecto de história indígena. Se por um lado somos levados a pensar que isso tem a ver simplesmente com características pessoais, não podemos perder de vista que nossas afinidades e aversões também são construídas socialmente.

Como mencionado anteriormente, a região Sul do Pará é habitada por diversas populações indígenas, entre elas os diferentes grupos Gavião (Gavião-Akrãtikateje, Gavião-Parkatêjê, Gavião-Kyikatêjê), os Suruí-Aikewara e os Awaeté-Parakanã, dentre muitos outros. Muitos cursos da Unifesspa contam com alunos e alunas provenientes de algumas dessas comunidades que adentram a universidade majoritariamente pelas vagas das ações afirmativas. Desde 2014, ano de fundação da Unifesspa a partir do desmembramento da Universidade Federal do Pará (UFPA), 58 alunos indígenas ingressaram nessa universidade. Já em 2015, somaram apenas quatro estudantes, sendo três por via das políticas afirmativas de cotas e um por outras formas de acesso. Em 2015, o número subiu para 20 estudantes e, em 2016, o foi de 34 . De acordo com a pesquisa Diagnóstico: Programa de Acolhimento Estudantil \& Diversidade; Indígenas e quilombolas na Unifesspa, publicada em janeiro de 2017, o ingresso de cerca de $95 \%$ dos indígenas na Unifesspa ocorre pelo Processo Seletivo Especial de Reserva de Vagas. ${ }^{14}$ De acordo com a pesquisa:

Dos 96 indígenas ingressantes, 52 são da etnia Gavião, 12 Karajá, 07
Xerente, 07 Guajajara e o restante se distribui entre as etnias Aikewara,
Guarany, Tembé, Aticum, Kaiapó, Xikrin e Chiiquitano. Parte dos indígenas
das etnias citadas, como os Karajá, Xiquitano, Guarany e Tembé, vivem em
diferentes aldeias do Território Indígena Mãe Maria do povo Gavião. Já os
indígenas Xerente residem no perímetro urbano de Marabá, com exceção de
uma indígena que também reside na TI Mãe Maria. A presença em maior
número do povo Gavião na universidade é justificada pela proximidade da
Terra Indígena Mãe Maria de Marabá, localizada no município Bom Jesus do
Tocantins, a menos de 29 km de distância. Do total de ingressantes 42 são

${ }^{14}$ https://proex.unifesspa.edu.br/images/conteudo/proex/Editais/PESQUISA DIAGNOSTICO Acolhimen to Estudantil e Diversidade 2016.pdf, p. 22. 
mulheres e 54 homens. Nas Unidades fora de sede registramos a presença de 03 (três) indígenas: 01 em Rondon do Pará (Gavião), 01 em Xinguara (Karajá) e 01 em São Felix do Xingu (Kayapó). ${ }^{15}$

Nesse cenário, cursos como o de Direito, por exemplo, contam com alunos e alunas indígenas em grande parte das turmas. A licenciatura em História do campus de Marabá, contudo, ainda tem poucos estudantes indígenas. Entretanto, professores, pesquisadores e estudantes preocupados com questões indígenas não são incomuns na comunidade acadêmica da Unifesspa.

Não obstante, dentre os estudantes da graduação em História ainda é perceptível a permanência de visões estereotipadas das populações indígenas. Ou seja, ainda são comuns os discursos tradicionais que pensam "um" índio preso a narrativas coloniais e isolado geograficamente. Dentre as comunidades indígenas próximas aos campi da Unifesspa, estão aquelas que habitam a Terra Indígena Mãe Maria, que está a menos de 70 quilômetros de Marabá. Dessa comunidade, é proveniente grande parte dos estudantes indígenas que frequentam diferentes cursos da Unifesspa. Contudo, a visão do isolamento geográfico dos indígenas, ainda persiste.

\section{As Experiências de 2016 e 2017}

Os alunos e alunas que ingressam na licenciatura em História começam a cursar as disciplinas da nucleação de história das américas já em seu segundo semestre, quando podem se matricular no curso "Sociedades Autóctones das Américas". O objetivo da disciplina é tratar de temas referentes às sociedades ameríndias antes do contato com os europeus, a partir de 1492. Tradicionalmente, os cursos que pensam sociedades ameríndias, nos períodos anteriores aos processos de colonização, dedicam mais tempo ou àquelas sociedades com grandes concentrações urbanas no momento do contato com os europeus ou àquelas que supostamente contavam com maior produção de cultura material de acordo com a historiografia tradicional. Exemplos de sociedades do contato são os mexicas (astecas), no complexo mesoamericano, e as sociedades andinas, em especial os incas. $\mathrm{O}$ exemplo mais comum de outras sociedades que deixaram grandes quantidades de vestígios materiais e arquitetônicos é o das sociedades maias, que recebem muita atenção da historiografia se comparadas a outras sociedades. O trinômio

\footnotetext{
${ }^{15}$ https://proex.unifesspa.edu.br/images/conteudo/proex/Editais/PESQUISA DIAGNOSTICO Acolhimen to Estudantil e Diversidade 2016.pdf, p. 22. O número 96 corresponde aos alunos que ingressaram desde 2010.
} 
astecas, maias e incas é, assim, um parâmetro frequentemente utilizado para a organização dos conteúdos de disciplinas que pensam as américas antes da invasão europeia (BITTENCOURT, 2003).

A atribuição da disciplina "Sociedades Autóctones das Américas", em 2016, destarte, foi dada à professora Maria Clara S. Carneiro Sampaio. O seu plano de curso se propunha a problematizar de que forma o estudo das sociedades ameríndias que existiam nas américas antes das invasões europeias é indissociável dos eventos posteriores que englobam os diferentes processos de colonização. Nesse sentido, as primeiras observações referentes às sociedades sobre as quais se produziram mais ou menos narrativas são mediadas pelas visões de mundo daqueles observadores europeus. Esses, uma vez na América, expressam-se não só por suas estruturas sociais e de pensamento, mas também transmitem interesses muito específicos para cada um dos territórios que julgam "descobrir" e sobre os quais tem o poder de relatar. ${ }^{16}$

Mostrou-se bastante desafiador analisar as sociedades autóctones das américas “antes" dos europeus, em virtude de maior facilidade de acesso às fontes resultantes das invasões. Entretanto, não se pôde deixar de procurar identificar, nos vestígios documentais, as estruturas sociais ameríndias apropriadas pelos poderes coloniais. Outro desafio percebido diz respeito à narrativa da suposta facilidade com que as sociedades invadidas foram submetidas militarmente pelos europeus.

Nesse sentido, procurou-se estruturar a disciplina de tal forma que se expandisse o recorrente estudo do trinômio astecas-maias-incas em uma perspectiva que dialogasse com a problemática da mediação das narrativas que os ibéricos produziram naqueles primeiros anos de invasão e domínio, principalmente no tocante ao Planalto do México e à região central das cordilheiras andinas. Por conseguinte, pretendeu-se desenvolver com os(as) discentes questionamentos sobre as razões que ainda sustentam a preponderância que mexicas, maias e incas têm sobre outras sociedades das américas, tanto na historiografia quanto no senso comum.

Os primeiros desafios começaram a se delinear ainda na fase de planejamento do curso. Confirmou-se a suspeita de que as traduções das pesquisas mais recentes sobre as sociedades americanas permaneciam rarefeitas, mesmo quando se buscava bibliografia sobre temas mais tradicionais, como as sociedades mesoamericanas. Pesquisas mais antigas, da mesma forma, permaneciam sem tradução. Ainda que se tenha uma série de

\footnotetext{
${ }^{16}$ Dialogamos, aqui, com a concepção de "relato" defendida por Michel de Certeau (2001).
} 
excelentes pesquisas brasileiras e estrangeiras publicadas em português, muitas obras e historiadores clássicos como María Rostworowski permanecem acessíveis majoritariamente em língua estrangeira.

Ainda na fase de concepção e organização do curso, imaginou-se que a escolha de autores latino-americanos, em detrimento de autores norte-americanos e europeus, pudesse contribuir para a discussão acerca do lugar de fala da produção historiográfica sobre as sociedades indígenas. Entretanto, como se encontrou muito pouco traduzido, acabou-se por pensar a escolha de textos com base na sua possibilidade de acesso, tanto a partir do acervo das bibliotecas pessoais dos professores como do acervo das bibliotecas da universidade. Naquele momento, as bibliotecas da Unifesspa contavam, basicamente, com os volumes de História da América Latina, organizados por Leslie Bethell, para cobrir os temas de história das américas. A parte dedicada às sociedades ameríndias antes da colonização conta com três capítulos, que se estendem por pouco mais de 100 páginas. Não havia traduções de outras coleções como Cambridge History of the Native People of the Americas (História dos Povos Nativos das Américas, em tradução livre), cujos volumes dedicados para a América do Sul são organizados por Stuart Schwartz e Frank Salomon.

Outro desafio percebido foi o fato de que as obras indicadas não estavam disponíveis em formato digital. Diferentemente de outros cursos que tratavam de temas de história do Brasil, teoria da história e história europeia, as versões digitais das leituras indicadas eram muito difíceis de ser localizadas e consultadas. Obras sobre história medieval, por exemplo, não só eram mais diversificadas no acervo da biblioteca, como eram facilmente encontradas em formato pdf ou de ebook.

A desconstrução de noções adquiridas no ensino básico é frequentemente um artifício didático empregado naquelas disciplinas introdutórias nos cursos do ensino superior. Destarte, grande parte das aulas que se pretendia ministrar partiriam da perspectiva de desconstruir as visões que alunos e alunas traziam de suas experiências, tanto no ensino fundamental como no ensino médio.

A primeira noção que a disciplina pretendia desconstruir era aquela da conquista supostamente fácil das armadas ibéricas, principalmente frente às sociedades mexicas e andinas. Posteriormente, ainda pensando nas numerosas sociedades mesoamericanas e andinas, seria proposto pensar a forma como intérpretes ibéricos do século XVI descreviam as práticas de sacrifício humano como provas cabais do barbarismo daquelas sociedades. Era nosso objetivo mostrar as formas de resistência aos processos 
coloniais, ao mesmo tempo que se compreenderia melhor que as vitórias europeias se deram graças às alianças com outras sociedades que tinham interesse na queda de Tenochtitlán. No tocante ao suposto barbarismo das práticas de sacrifícios rituais, que tanto chocou os ibéricos modernos, tentaríamos compreender como aquelas imagens acompanharam as visões sobre essas sociedades nos séculos seguintes às lutas da conquista e como podem ser relativizadas se pensarmos algumas das práticas violentas empregadas por europeus naquele período.

Grande parte das poucas noções e imagens que me foram trazidas eram provenientes não das aulas de história do ensino médio, mas de umas poucas produções cinematográficas e de jogos para computador. A impossibilidade de desconstruir conceitos que não eram familiares para grande parte dos estudantes impulsionou a necessidade de mudança na forma como se tinha planejado a disciplina. ${ }^{17}$

Nesse mister, ao invés de se discutir a desconstrução de pré-conceitos alimentados pelos conteúdos dos cursos de história do ensino médio, bem como o pouco espaço que essas sociedades recebiam nos livros didáticos, acabou-se por se desenvolver uma reflexão das razões por trás dos silêncios que acompanham grande parte dos temas de história das sociedades indígenas no Brasil e em outras nações das Américas. Ao fim do curso, uma série de alunos e alunas ainda relatou que grande parte dos conteúdos dos textos e das aulas expositivas tinham sido completamente novos para eles. Conquanto grande parte deles tinha sido exposta a imagens dos templos (pirâmides) de Teotihuacán, destino turístico comum daqueles que visitam a Cidade do México, e às imagens de Machu Pichu, poucos tinham desenvolvido qualquer interesse em aprender mais sobre aquelas sociedades ameríndias.

Nas primeiras aulas do curso, os estudantes foram questionados sobre eventuais interesses em pesquisar temas de história indígena local, a partir, por exemplo, da coleção de cerâmicas da Casa da Cultura de Marabá. ${ }^{18}$ Não houve interesse naquele

\footnotetext{
${ }^{17}$ A disciplina tinha sido pensada para percorrer cinco núcleos que variavam em quantidade de aulas e de leituras dedicadas a cada um deles: 1. Teorias de povoamento e outros temas; 2. sociedades mesoamericanas; 3. sociedades andinas; 4. Arqueologia amazônica e 5. Sociedades indígenas da América do Norte e do Ártico. Sendo que os conteúdos do primeiro e do quarto núcleo foram planejados para serem trabalhados majoritariamente a partir de aulas expositivas, em função de que sobre sociedades ameríndias que se desenvolveram no atual Canada e Estados Unidos quase nada em português foi encontrado.

18 A Fundação Casa da Cultura de Marabá é uma instituição de pesquisa e preservação histórico ambiental mantida pelo município. Dentre as coleções do setor de antropologia estão cerâmicas de diferentes grupos indígenas.
} 
momento, entretanto, ao fim do curso, em uma sala com cerca de 15 estudantes, apenas uma aluna iniciou uma pesquisa sobre arqueologia amazônica.

É digno de nota que, a despeito da percepção presente no senso comum (de que os povos indígenas no Brasil estão atualmente restritos à região Norte e, de forma especial, à Amazônia), os alunos demonstravam surpresa diante das pesquisas arqueológicas $^{19}$ que retratavam as várzeas Amazônicas como ocupadas por concentrações populacionais em escala urbana. A reação e muitos dos questionamentos dos alunos nas disciplinas ministradas pela professora Valeria Melo deixavam clara a percepção de que, no momento da invasão, inclusive a costa brasileira era habitada por sociedades autóctones. A presença indígena no interior era percebida em grande medida como resultante das migrações de pequenos grupos que fugiam da violência do processo de colonização no litoral brasileiro. Assim, algumas das imagens que emergiam com força era da floresta como inabitada e intocada, bem como a do índio tupi que, diante do mar, observa calmamente a chegada das caravelas ou a celebração da primeira missa, imagens essas tão comuns nos livros didáticos.

Trabalhando os textos de arqueologia paralelamente às relaciones escritas por Gaspar de Carvajal (1542) e Cristobal de Acuña (1641), os discentes foram paulatinamente compreendendo como alguns documentos reforçavam muitos dos dados evidenciados por pesquisas arqueológicas. Foram vendo que tanto os vestígios arqueológicos quanto os cronistas em questão desconstruíam a ideia da floresta como um ambiente hostil que teria inibido o crescimento populacional e o desenvolvimento cultural das sociedades da Amazônia brasileira, colocando-as em uma escala evolutiva inferior aos povos da Mesoamérica e dos Andes. Um dos objetivos de abordar as pesquisas arqueológicas mais recentes era questionar o entendimento das sociedades autóctones americanas por meio de esquemas que tendiam a hierarquizá-las a partir dos vestígios materiais deixados por elas.

Os estudantes se mostraram especialmente surpresos ao descobrir a quantidade e riqueza dos sítios arqueológicos amazônicos, com a beleza dos diferentes tipos de cerâmica, com a ideia do manejo do solo e das espécies vegetais. Ficaram surpresos, sobretudo, ao saber que alguns dos sítios considerados importantes no cenário da arqueologia nacional ficam exatamente no estado do Pará, e alguns próximos à Marabá,

\footnotetext{
${ }^{19}$ Como é o caso dos trabalhos de Anna Roosevelt e Eduardo Góes Neves para citar apenas alguns nomes.
} 
como é o caso da Gruta do Gavião e da Gruta do Pequiá, localizadas na Serra dos Carajás. ${ }^{20}$ Uma das perguntas que surgiu foi "por que isso não é ensinado na escola?”.

É importante enfatizar, entretanto, que não é incomum alunos demonstrarem resistência às leituras da área de arqueologia. Alguns se mostram incrédulos sobre a importância de estudar sociedades que supostamente não existiriam mais. Com o objetivo de tentar superar esse tipo de resistência, foi inserido no programa da disciplina um primeiro módulo intitulado "Por que estudar sobre as sociedades autóctones". Este módulo foi composto por leituras que visavam a problematizar o contexto e as bases teóricas da construção da imagem estereotipada e preconceituosa acerca dos povos indígenas das américas, bem como de outros que falam da importância do ensino de história indígena.

As discussões empreendidas, inicialmente, no âmbito da disciplina "Sociedades Autóctones" vão sendo paulatinamente ampliadas em outras disciplinas ao longo do curso. Nas turmas que se encontram mais próximas à conclusão, se as propostas de pesquisa que visam a estudar história indígena por meio do diálogo com arqueologia ainda são poucas, temos alunos com projetos que enveredam pela temática de outras formas. O interesse de pesquisa, por exemplo, de uma estudante sobre como a questão indígena é abordada nos livros didáticos de história e de outra pesquisa acerca da história dos Gavião.

\footnotetext{
${ }^{20}$ Caverna da Pedra Pintada, no município de Monte Alegre, Taperinha em Santarém para citar mais alguns exemplos.
} 


\section{Algumas Conclusões}

Acreditamos que o fortalecimento de uma cultura universitária que envolva estudantes indígenas possa concorrer para que o contato cotidiano propicie possibilidades mais ricas de acesso às múltiplas narrativas sobre cultura e história indígena. Contudo, faz-se necessário pontuar que a pouca atenção destinada a essa temática na educação básica, bem como a inadequação de materiais didáticos disponíveis ampliam as lacunas no processo de formação docente. Um dos desafios ainda continua sendo levar para as salas de aula as discussões desenvolvidas no campo das pesquisas acadêmicas.

Outra questão a ser considerada talvez seja a dificuldade de se compreender o processo de formação da história do Brasil de forma conectada com as histórias das américas. Por outro lado, parece que as discussões envolvendo a história da África, por exemplo, como parte constituinte da história do Brasil tem avançado de forma mais significativa. Nesse sentido, é oportuno questionar de que forma a educação para as relações étnico-raciais, no que tange à construção da negritude, é articulada com uma perspectiva de histórias conectadas entre Brasil e África. ${ }^{21} \mathrm{O}$ mesmo não parece tão óbvio quando se analisa que os estudos sobre os povos indígenas brasileiros, em larga medida, podem resultar em reflexões mais significativas se também pensados de maneira conectada com outras histórias ameríndias.

Pensar a história do Brasil de maneira conectada à história de outras nações sulamericanas não é novidade, seja para a educação básica ou superior (BITTENCOURT, 2003). Contudo, as questões indígenas permanecem silenciadas, mesmo com o tímido crescimento da preocupação de incluir com maior consistência temas de história da américa nas grades dos ensinos fundamental e médio, inclusive com a preocupação em relação à formação de professores que atuam na área. Talvez esse cenário resulte da interpretação segundo a qual a história indígena encontra-se separada da história brasileira da mesma maneira que a história do Brasil está separada da história das américas.

\footnotetext{
${ }^{21}$ Para ampliar as reflexões sobre história conectada, ver SUBRAHMANYAM, Sanjay (1997).
} 


\section{REFERÊNCIAS}

ALBERTI, Verena. Proposta de material didático para a história das relações étnicoraciais. Revista História Hoje, v. 1, n. 1, p. 61-88, 2012.

ALMEIDA, Maria Regina Celestino de. Os índios na História do Brasil no século XIX: da invisibilidade ao protagonismo. Revista História Hoje, v. 1, n. 2, p. 21-39, 2012.

BERGAMASCHI, Maria Aparecida; GOMES, Luana Barth. A Temática Indígena na Escola: ensaios de educação intercultural. Currículo sem Fronteiras, v. 12, 2012, p. 5369.

BITTENCOURT, Circe Maria Fernandes. Ensino de história da América: reflexões sobre problemas de identidades. Revista Eletrônica da ANPHLAC, v. 4, p. 01-11, 2005.

BITTENCOURT, Circe Maria Fernandes e BERGAMASCHI, Maria Aparecida. Dossiê: Ensino de História indígena, Revista História Hoje, v. 1, n. 2, 2012.

2005.FLEURY, Reinaldo M. Intercultura e Educação. Revista Brasileira de Educação, Maio/Jun/Jul/Ago No 23, 2003.

CUNHA, Manuela Carneiro da. "O Futuro da Questão Indígena. Estudos Avançados”, São Paulo, v. 12, p. 1-16, 1994

CUNHA, Manuela Carneiro da; e VIVEIROS DE CASTRO, Eduardo Viveiros de (Org.). Etnologia e História Indígena na Amazônia: Novas Perspectivas.São Paulo: FAPESP e Núcleo de História Indígena e Indigenismo, 1993 (volume I).

FERNANDES, Antonia Terra de Calazans. Ensino de história e a questão indígena. Revista História Hoje, v. 1, n. 2, p. 255-266, 2012.

FERRAZ, Iara. De Gaviões à Comunidade Parkatêjê: uma reflexão sobre processos de reorganização social, 212 f. Tese (Doutorado em Antropologia Social) - Universidade Federal do Rio de Janeiro, Rio de Janeiro, 1998.

FERRAZ, I.; LADEIRA, Maria Elisa. Os povos indígenas da Amazônia oriental e o Programa Grande Carajás: avaliação e perspectivas. In: Hébette, Jean. (Org.). O cerco está se fechando. 1.aed.Petrópolis / RJ: Vozes, 1991, v. , p. 130-141.

MEDEIROS, Juliana Schneider. Educação escolar indígena: a escola e os velhos no ensino da história kaingang. Revista História Hoje, v. 1, n. 2, p. 81-102, 2012.

MONTEIRO, John Manuel. Tupis, Tapuias e Historiadores, Campinas: Tese de Livre Docência, 2001.

NEVES, Eduardo Gomes. O Velho e o Novo na Arqueologia Amazônica. Revista USP, São Paulo, n. 44, pp 86-111, dezembro/janeiro, 1999

OIT. Convenção no 169 sobre povos indígenas e tribais em países independentes e Resolução referente à ação da OIT sobre povos indígenas e tribais. 2.ed. Brasília, 2005. p.47-48.

OLIVEIRA, Susane Rodrigues. Ensino de História Indígena: Trabalhando com Narrativas Coloniais e Representações Sociais. In: PORTUGAL, Ana Raquel; HURTADO, Liliane Regalado Cossio (orgs.). Representações Culturais da América Indígena. São Paulo: Editora UNESP, 2015. 
PACHECO DE OLIVEIRA, João. Mensurando alteridades, estabelecendo direitos: práticas e saberes governamentais na criação de fronteiras étnicas. In. Pacheco de Oliveira. O nascimento do Brasil e outros ensaios: "pacificação", regime tutelar e formação de alteridades. Rio de Janeiro: Contra Capa, 2016.

PASSOS, Joana Célia dos. "Discutindo as relações raciais na estrutura escolar e construindo uma pedagogia multirracial e popular". In. Nogueira, João Carlos (Org.). Multiculturalismo e a pedagogia multirracial e popular. Florianópolis: Editora Atilènde, 2002.

PEREIRA, Airton dos Reis. De Posseiro ao Sem Terra: a luta dos trabalhadores rurais pela posse da terra no sudeste do Pará. A luta pela terra no sul e sudeste do Pará. Recife: Editora UFPE, 2015.

PEREIRA, Júnia Sales. Diálogos sobre o exercício da docência no contexto de recepção das Leis 10.639/03 e 11.645/08. Educação e Realidade, v. 36, 2011, p. 147-172.

ROOSEVELT, Anna. Arqueologia Amazônica. In: CUNHA, Manuela Carneiro da (org.). História dos Índios no Brasil, São Paulo: Companhia das Letras, 1998.

RUSSO, Kely e PALADINO, Mariana. A lei n. 11.645 e a visão dos professores do rio de janeiro sobre a temática indígena na escola. Revista Brasileira de Educação v. $21 \mathrm{n}$. 67, 2016.

SANTOS, Eduardo Natalino dos. "Da importância de pesquisarmos história dos povos indígenas nas universidades públicas e de a ensinarmos no ensino médio e fundamental" Mneme (Caicó. Online), v. 15, p. 9-20, 2014.

SILVA, Edson. O ensino de História Indígena: possibilidades, exigências e desafios com base na Lei 11.645/2008. Revista História Hoje, v. 1, no 2, p. 213-223 - 2012.

SILVA, Geovani José da. Categorias de entendimento do passado entre os Kadiwéu: narrativas, memórias e ensino de história indígena. Revista História Hoje, v. 1, n. 2, p. 59-79, 2012.

SILVA, Idelma Santiago da; PENÃRROCHA, Pere Petit; RAMOS Jr., Dernival Venâncio Ramos Júnior; PEREIRA, Airton dos Reis. Projeto Político Pedagógico. Licenciatura em História. Marabá, 2013.

VIVEIROS DE CASTRO, Eduardo. No Brasil todo mundo é índio, exceto quem não é. In. Sztutman, Renato (Ed.). Encontros. Rio de Janeiro: Azougue, 2008, p.136-160. 